\title{
Formwork with Variable Geometry for Concrete Shells Production Technology
}

\author{
Vitalijs Lusis \\ Riga Technical University, \\ Faculty of Civil Engineering, Concrete mechanics laboratory \\ Address: 1 Kalku Street, Riga, LV-1658, Latvia
}

\begin{abstract}
One of the main constructive materials in the building sphere is a precast concrete and fiber concrete. It is well influenced by scientific research basis, development and implementation of progressive technologies. The fiber concrete it is an ideal material with practically unlimited number of shapes. A nomenclature of concrete articles increases, it is working on different shape formation and processing. While preparation for this document started with the concept fabrication, it is necessary to understand the methods of construction variable geometry formwork of concrete thin-shell surfaces, both past and present as a point of departure. An understanding of this background helps provide an essential foundation for the exploration of new potential advances in the field of thin-shell construction. Obviously that is the reason for fiber concrete to be the most widespread constructive building material all over the world. In the article are considered shell development technology features and is evaluated technical and economical effectiveness of concrete shells with thin walls. Now variable geometry systems from flexible materials are developing and improving, there is a great potential followed by modern events in concrete technology. The results of laboratory experiments have proved that the technology can be used for fibro concrete shell production and construction.
\end{abstract}

Keywords - concrete shells, shells production technology, glass fibers, fiberconcrete.

\section{INTRODUCTION}

Recent developments in concrete technology have led to ultra-high performance fibre reinforced concrete with revolutionary performance in tension and compression. In fact, ultra high performance fibre reinforced concrete can be seen as a completely new construction material and its possibilities are still to be revealed. Fibre reinforced concrete use leads itself to a variety of innovative designs as a result of its many desirable properties. Not only the higher quality contemporary construction materials capable of resisting tension forces contributed to this development, but also the theoretical knowledge gained from the late 19th century up to the present day. Earlier the engineers were restricted by constructional possibilities. The modern era of shell construction is recognized by the trend towards greater spans and thinner shells.

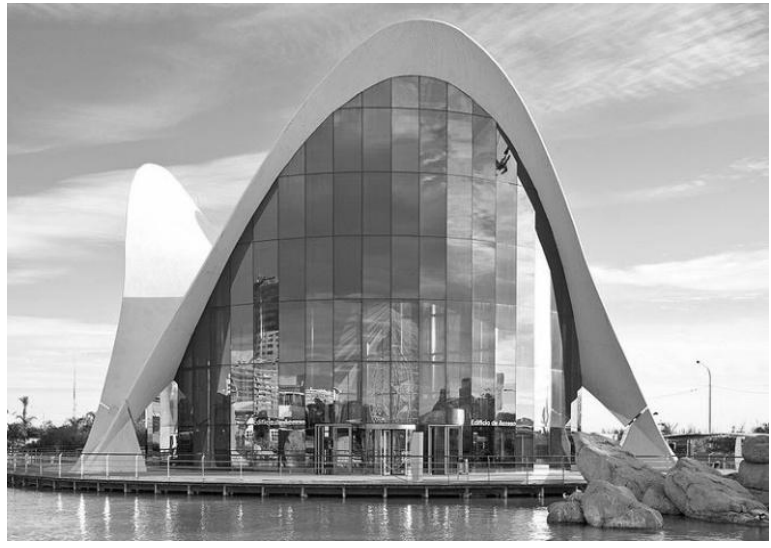

Figure 1. L'Oceanogràfic in Valencia, Spain — an open-air oceanographic park, architect Félix Candela
Modern shell structures span larger column-free areas from $100 \mathrm{~m}$ and more and, more important, with thinner thicknesses than the traditional domes. Thin concrete shell structures can cover the roofs of various buildings efficiently and aesthetically. The search for new spatial structures resulted in widespread pioneering with new types of shells.

Architecture form has got a thin concrete shell created in the form of circles, hyperboloids and paraboloids and of double curved shapes with undefined free-form shapes (Deconstructivism). In order to achieve required geometrically complicated forms and surfaces of textured concrete is necessary a flexible and adjustable formwork system $[1,2,3]$. The desire to reduce the thickness is understandable as the dead weight of the shell represents the major portion of the total load.

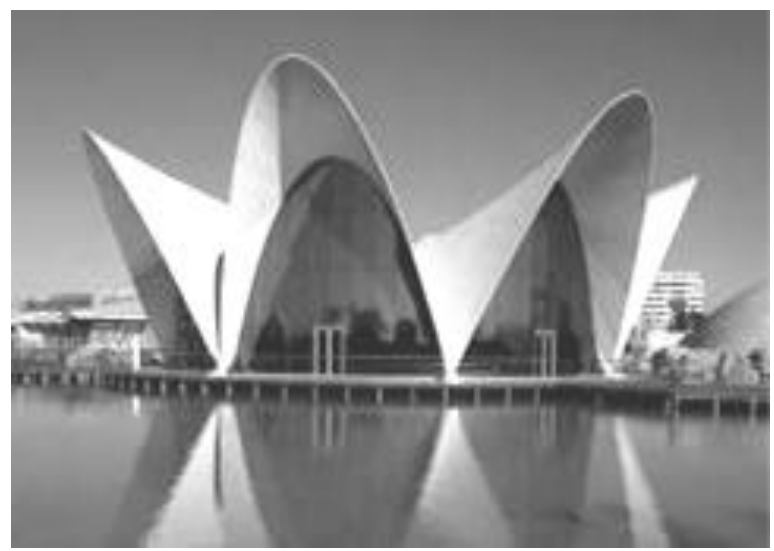

Figure 2. Los Manantiales Restaurant (1957) in Xochimilco, Mexico by Felix Candela 
Most shells are constructed in a conventional manner: pouring concrete on a formwork. Other possibilities are the use of airform moulds or stressed membranes combined with sprayed concrete. Although the number of repetition is often not very high, prefabricated elements may be used.

If one shell has to be chosen as being the inspiration for a complete generation of new shell engineers, it must be the Los Manantiales Restaurant in Xochimilco, Mexico. Felix Candela completed the shell in 1957 and the design was that much of a success that, at the present day, it has been copied several times.

Jorg Schlaich designed a Xochimilco-like shell in 1977 in Stuttgart, Ulrich Muther constructed the Seerose in 1983 in Potsdam and in just recently in 2002 in Valencia another look-a-like has been constructed by Santiago Calatrava: the new l'Oceanografic see figure 1. Furthermore, famous shell builder Heinz Isler was inspired by the slenderness of the Manantiales restaurant. The original Xochimilco shell, seen on figure 2, is an octagonal groined vault composed of four intersecting hypars.

\section{MATERIALS AND METHODS}

Tasks of laboratory experiments: production and achievement of different kind shells, including domeshaped constructions, clearing up the shell production technological features and technological process advantages, effectiveness, a visual attraction and advantages of products. Laboratory experiment to create on formwork with variable geometry was elaborated Latvian invention patent Nr. LV14308 [4]. Use of a formwork advantages can be mentioned as follows: flexible shapes (being curved created surfaces are of architecturally and technologically complicated shapes), smooth concrete surface quality, formwork weight and volume of tissue is very small comparing to plywood or steel formwork.

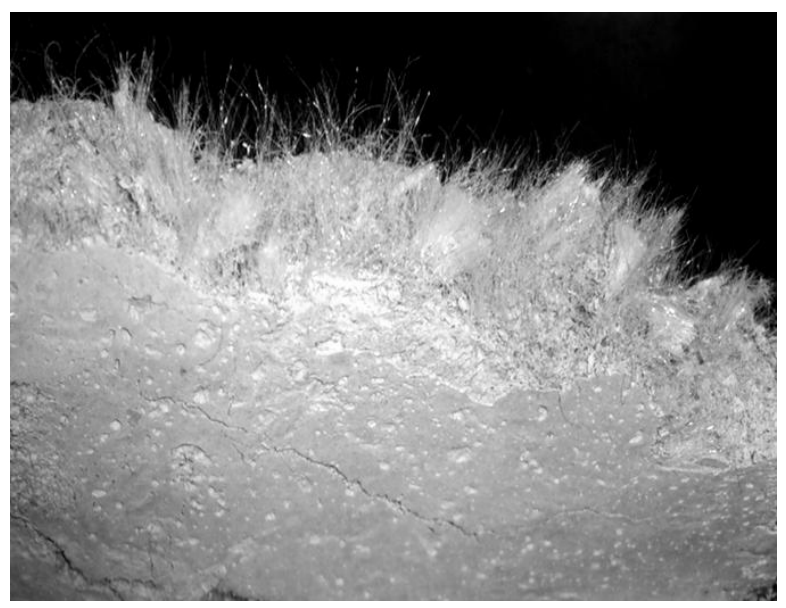

Figure 3. Short AR glass fibers homogeneously distributed in the concrete shell
Despite the purpose of variable geometry formwork and their usage conditions, the material of formwork should have a sufficient tensile strength (calculated) and low weight, should be resisting to weather impacts, flexible, fireproof (at least the material should be fire extinguished), heatproof and frostresisting. The requirements are fulfilled when using composite materials (created on synthetic fibro basis).

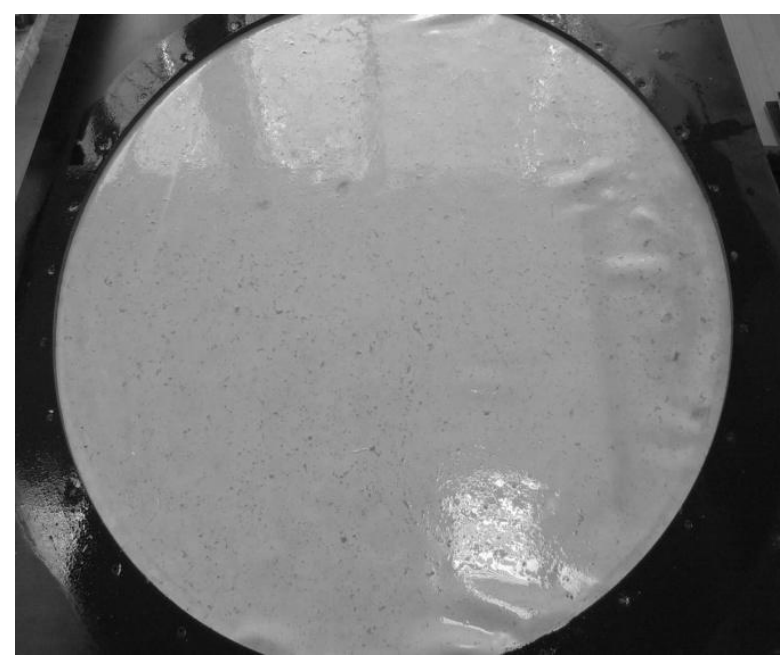

Figure 4. Formwork construction

Experiments in order to create concrete shell production technology process were made in 2013 in the Riga Technical University in laboratory in order to create an effective shell production technology. Was produced a formwork with variable geometry by gravity. Formwork construction: veneer $1000 \times 1000 \times 9$ $\mathrm{mm}$, rubber sheet $1000 \times 1000 \mathrm{~mm}$, height of frame borders is $9 \mathrm{~mm}$ see figure 4 . Tasks of laboratory experiments: production and achievement of different kind shells, including dome-shaped constructions, clearing up the shell production technological features and technological process advantages, effectiveness, a visual attraction and advantages of products. In the reported work, on the flat surface mould was imposed and smoothed down (forming a thin layer) glass fiberconcrete mix.

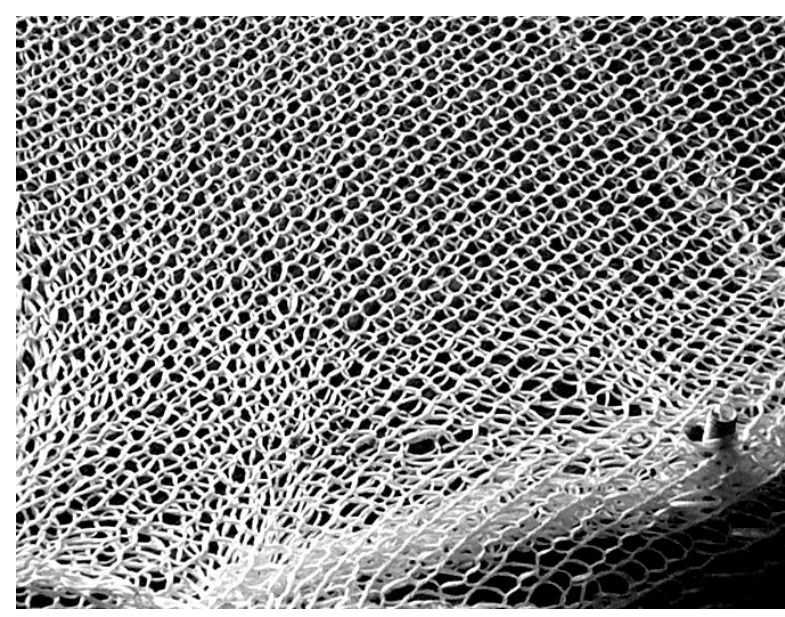

Figure 5. Knitted fabric for concrete shell reinforcement 


\section{Lusis V. FORMWORK WITH VARIABLE GEOMETRY FOR CONCRETE SHELLS PRODUCTION TECHNOLOGY}

After concrete mould was by forming a moderate curvature shell. As concrete was hardened mould was kept constant value. Then a mould was out and shell was demolded.

A fresh concrete shell done by such speed, so that there won't appear technological cracks on shell surface. For increasing limits of deformation of a fresh concrete there are used special supplements in its mix, for instance, various desired water-soluble polymers or waterproof polymer emulsions. There are also used different kinds of material fibro reinforcement in concrete mix, which after concrete hardening improves its constructive features.

The shell's should be reinforced:

One solution can be short AR glass fibers homogeneously distributed in the concrete see figure 3. Another option is use of knitted AR glass fibre fabrics (fulfilled by concrete) see figure 4 and placed distance one to another the thickness of the structure.

Knitted fabric reinforced concrete matrix composites have grew rapidly during recent years. Such materials are exhibiting attractive mechanical properties including high energy absorption and impact resistance. Shell production: mould is laid a concrete or fibro concrete mix on prepared formwork flat surface and it is smoothed see figure 5 after molding process should be finished before starting concrete mix hardening. Not allowing the concrete mix hardening start, the formwork surface is curved till defined shell dimensions. A fresh concrete shell is done by such speed, when tension pressure in a fresh concrete mix can be relaxed so that mix tension deformations wouldn't increase its limits of deformations, so that there won't appear technological cracks on shell surface. For increasing limits of deformation of a fresh concrete there are used special supplements in its mix, for instance, various desired water-soluble polymers or waterproof polymer emulsions.

Yarns loops are arranged in structures. In woven fabric, threads traditionally are running horizontally and vertically. Contrary, in the case of knitted fabric, strands are forming loops see figure 6 .
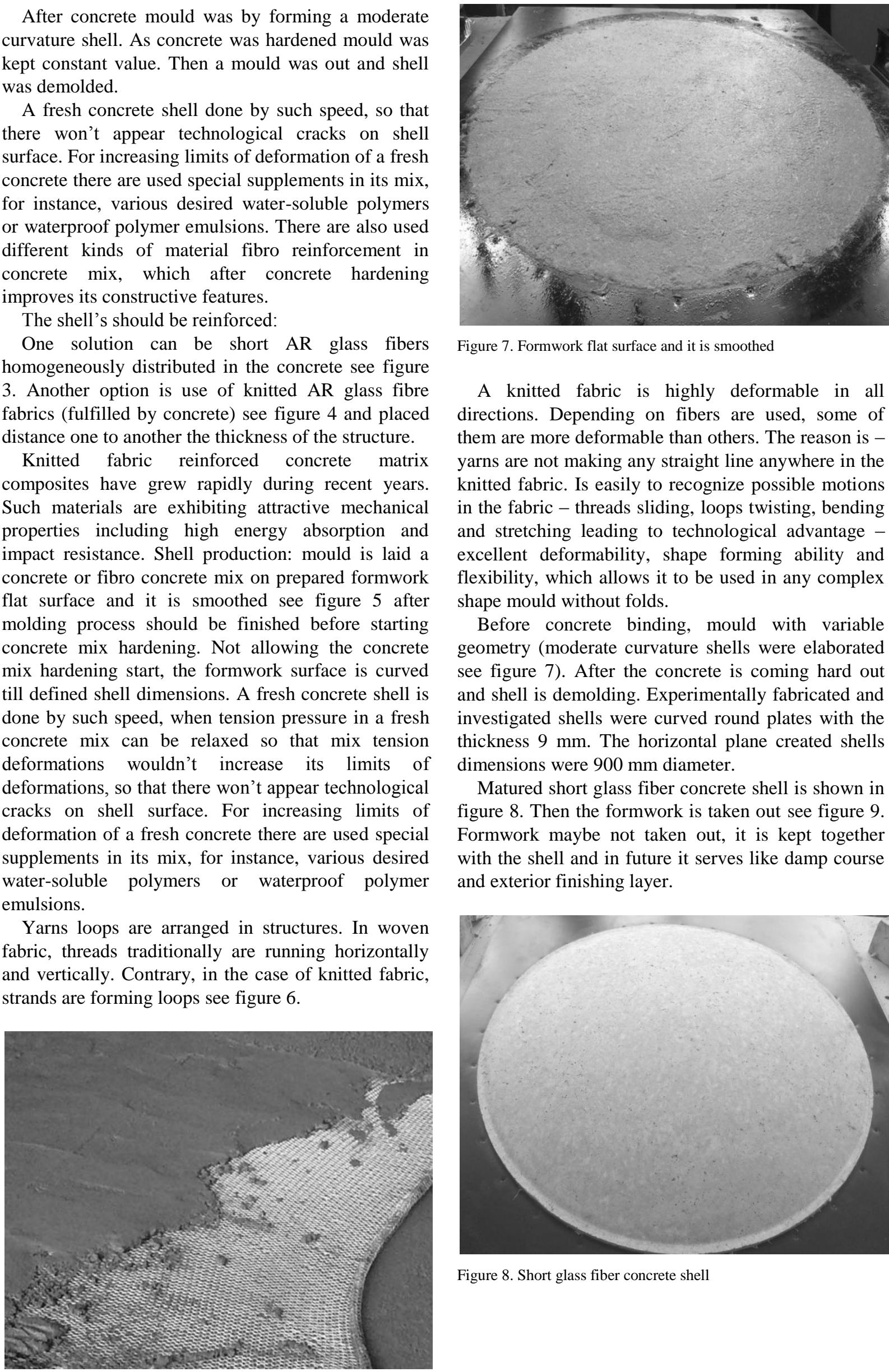

Figure 7. Formwork flat surface and it is smoothed

A knitted fabric is highly deformable in all directions. Depending on fibers are used, some of them are more deformable than others. The reason is yarns are not making any straight line anywhere in the knitted fabric. Is easily to recognize possible motions in the fabric - threads sliding, loops twisting, bending and stretching leading to technological advantage excellent deformability, shape forming ability and flexibility, which allows it to be used in any complex shape mould without folds.

Before concrete binding, mould with variable geometry (moderate curvature shells were elaborated see figure 7). After the concrete is coming hard out and shell is demolding. Experimentally fabricated and investigated shells were curved round plates with the thickness $9 \mathrm{~mm}$. The horizontal plane created shells dimensions were $900 \mathrm{~mm}$ diameter.

Matured short glass fiber concrete shell is shown in figure 8 . Then the formwork is taken out see figure 9. Formwork maybe not taken out, it is kept together with the shell and in future it serves like damp course and exterior finishing layer.

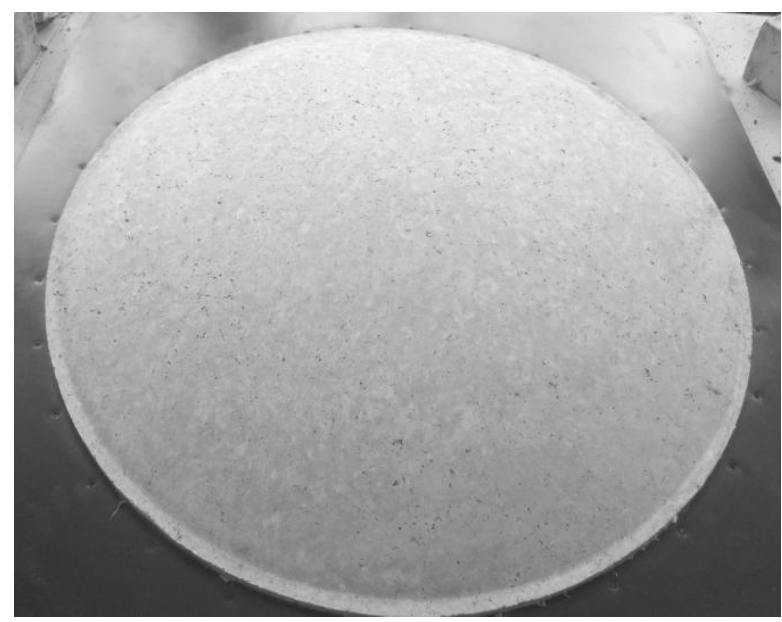

Figure 8. Short glass fiber concrete shell

Figure 6. Concrete shell fabrication reinforced by three layers of knitted glass fiber fabric 


\section{RESULTS AND DISCUSSION}

Recently, become relevant methods of forming prefabricated thin-shell concrete structures that can are allowed to deflect into naturally occurring funicular geometries, producing molds for lightweight compression vaults and stiff double curvature wall panels. The reduction in material, can be as high as 200-300 percent. Variable geometry formwork that can be formed through the simple act of inverting the tension curves obtained by a loaded material sheet. In this instance the symmetrical inversion of tension and compression geometries is perfectly matched by the symmetrically opposite resistance capacities of the materials involved, i.e. rubber or fabric in tension and the concrete in compression. These simply constructed structural components formed with flat textile sheets are compatible with flat sheet reinforcing such as knitted glass fiber textiles and AR glass fiber cloth.

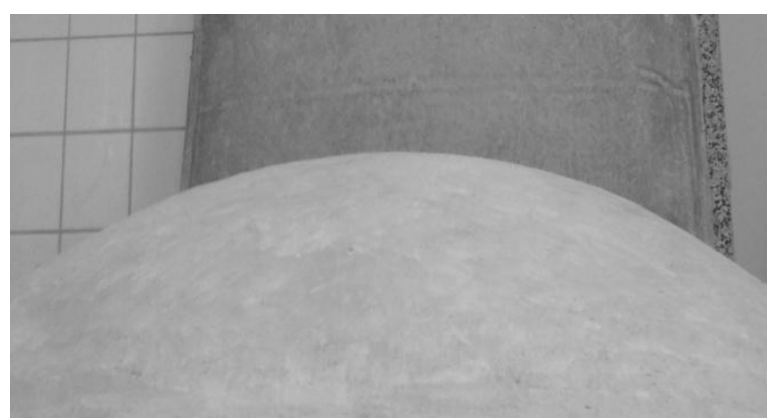

Figure 9. Concrete shell geometry

Economical and practical effectivity for a wide invention of progressive constructions with a modern design at new construction building principles where as formwork are used variable systems composed of flexible materials. Existing views about techniques and technology of constructions building from monolith concrete mostly is based on plane construction building experience.

Existing views about techniques and technology of constructions building from monolith concrete mostly is based on plane construction building experience. Provide an ideal concrete solution for formwork without any restricting factors connected to complicated geometry. Nowadays systems from flexible materials are developing and improving, new technologies are created. The technology has got a big potential followed by modern events in concrete production and development.

The offered new technology formwork with changeable form allow using them effectively as complete flexible and adjustable formwork systems, in order to create geometrically complicated architecture forms, at the same time not losing the strength indexes of constructed surfaces. New technology is foreseen for plain structures, that allows to create and have different shells, including domelike structures, in one direction curved shell, in two directions curved shell etc., for example, for building roof covering structures. Variable gravity mould use is an approach with a set of advantages among thin wall structural element fabrication technologies.

During the experiments were made shell two variants shells reinforcement: shell is reinforced by uniformly distributed short glass fibers and shell is reinforced by weft knitted glass fiber textiles.

The use of fiber-reinforced concrete in structures with high physical-mechanical characteristics makes it possible to reduce the weight and costs of the structures, to simplify the technology of their production, to reduce or completely eliminate the reinforcement labor, at the same time increasing reliability and durability.

\section{CONCLUSION}

The results of laboratory experiments show and proved that the technology can be used for fibro concrete shell production and construction. Formworks with variable geometry provide an ideal concrete solution without any restricting factors connected to complicated geometry. Shells reinforced by chopped glass fibre bundles as well as by knitted glass fibre fabric were fabricated.

Formwork with variable geometry give new opportunities in modern architecture, which is impossible using traditional formwork and allows to speak about its advantages, emphasizing the most effective usage sphere, small weight, possibility of multiple usage affects positively its usage in building sphere. It also allows engineers and architects a freedom to explore the shaping of concrete that has been elusive due to the complexities of the formwork.

\section{$\mathrm{V}$ ACKNOWLEDGMENTS}

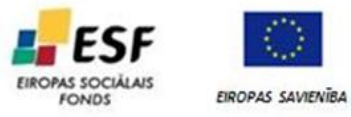

This work has been supported by the European Social Fund within the project «Support for the implementation of doctoral studies at Riga Technical University».

\section{REFERENCES}

[1] Lusis V. Production Technology for Concrete Shells Using Pneumatic Formwork with Variable Elevation// Sc. Proceeding of Riga Technical University, Construction science, 2011, P. 35-39.

[2] Krasnikovs A., Lusis V., Lapsa V., Zaleskis J., Zaharevskis V. and Machanovskis E., Concrete shells reinforced by glass fibers, Sc. Proceedings of Riga Technical University, Transport and engineering, 6, 2012, 6.p. (submitted 2012).

[3] Lusis V., Harjkova G., Machanovskis A., Kononova O., Krasnikovs A., Technology for concrete shells fabrication reinforced by glass fibers. „Civil engineering '13”, Jelgava, Conference proceedings. 2013, p. 5.

[4] Lapsa V., Krasnikovs A., Lusis V. Betona plānsieniņu čaulu veidošanas tehnoloğiskais process, Latvian invention patent Nr.14308, (21.01.2011) 